Original Research

\title{
Molecular Cloning, Expression Analysis and Subcellular Localization of LEAFY in Juglans mandshurica Maxim
}

\author{
Chunping Liu ${ }^{1,2}$, Xiujun Lu ${ }^{1,2}$, Jiaxing Song ${ }^{1,2}$, Qiang Zhou ${ }^{3}$, Xiaomei Sun ${ }^{1,2}$, \\ Jifeng Deng ${ }^{1,2}$, Lijie Zhang ${ }^{1,2 *}$ \\ ${ }^{1}$ College of Forestry, Shenyang Agricultural University, Shenyang, Liaoning Province, People's Republic of China \\ ${ }^{2}$ Key Laboratory of Forest Tree Genetics and Breeding of Liaoning Province, Shenyang, Liaoning Province, \\ People's Republic of China \\ ${ }^{3}$ Forestry Development Service Center of Liaoning Province, People's Republic of China
}

Received: 11 June 2021

Accepted: 18 September 2021

\begin{abstract}
Juglans mandshurica is a precious timber and economic tree species in Northeast China. Because of the reproductive characteristics of this species, such as long childhood and dioecious, the flowering period of male and female flowers is different, which directly affects the sexual reproduction process such as flowering and pollination. At present, the molecular mechanism of dioecious flowering of J. mandshurica is not clear. In this study, the cDNA sequence of a crucial gene involved in plant flowering, LEAFY $(L F Y)$ was cloned from J. mandshurica by homologous cloning, and the expression in different organs at various developmental stages, and the subcellular localization of the gene were analyzed. $L F Y$ in J. mandshurica was found to possess high homology (over 79\%), and a similar structure and function to LFY in other species, and was cloned and named JmLFY (GenBank: KX364241). The results of fluorescence quantitative real-time PCR analysis revealed that $J m L F Y$ was expressed in different organs, and that expression increased significantly before the early development stage of staminate inflorescence, the anther formation and pollen dispersal stage, pistillate inflorescence sprouting and flower development stage, and the pollination and late stage of zygotic embryo development. Expression of the green fluorescent protein fusion $J m L F Y$ gene in onion epidermal cells was localized to the nucleus and cytoplasm. Our results indicate that the $J m L F Y$ gene is the key transcription factor involved in flower formation and development in J. mandshurica. These findings provide information that may help to overcome the bottleneck caused by the long juvenile period and asynchronous female and male flowers of the species in the future.
\end{abstract}

Keywords: Juglans mandshurica, molecular cloning, expression analysis, LEAFY

*e-mail: Zlj330@syau.edu.cn 


\section{Introduction}

Flowering symbolizes the transformation from vegetative to reproductive growth in plants, and is a complex physiological and biochemical process regulated by genetic and environmental factors, including hormone signaling, photoperiodic induction, and temperature changes [1-4]. Recently, considerable progress has been reported regarding the key genes involved in flower formation, and their correlation with flowering pathways [5-7]. The model plant Arabidopsis thaliana has been studied comprehensively, and used in research investigating the genetic mechanisms underlying plant flowering. Arabdiopsis thaliana flowering is regulated by a complex signaling network, which can be classified into four stages: (1) the plant responds to environmental and endogenous signals and initiates reproductive growth via vegetative growth, which is regulated by flowering time genes, such as CONSTANS $(\mathrm{CO})$, FLOWERING LOCUS C (FLC), SUPPRESSOR OF OVEREXPRESSION OF CONSTANS ( $S O C 1$ ), and FLOWERING LOCUS $\mathrm{T}$ (FT) [8-13]; (2) floral meristem identity genes, such as LEAFY $(L F Y)$ and APETALA1 (APl), are activated by signals from stage (1) [14-15]; (3) floral-determination genes, such as FRUITFULL (FUL) and APETALA3 (AP3) are activated by meristem identity genes [16-19]; and finally, (4) organ construction genes are activated, which arrange the relevant cells and tissues into four floral organs [20].

$L F Y$ is a crucial gene for plant flowering, and is involved in most of these four stages. $L F Y$ is expressed before other meristem identity genes [21-22]; it integrates flowering signals from the previous stage (such as long-day promotion and GA pathways, which differ from flowering time genes [23] and is a key activator of downstream APl (functions as both a floral meristem identity gene and a floral determining gene) and the floral organ determining genes, subsequently inducing the expression of floral organ construction genes [24].

Real-time fluorescence quantitative PCR (qRTPCR) has shown that $L F Y$ expression differs in a temporal and spatial manner, especially in different plants. FLORICAULA (FLO), a homolog of $L F Y$ in Antirrhinum majus, is expressed in a temporal manner in the floral meristem, sepal, petal, and carpel in sequence, but not in the stamen [25-27]. In Populus tomentosa, $P T L F$ is expressed in developing inflorescence, and in the adjacent leaves and leaf buds [28]. BrpLFY from Brassica rapa subsp. pekinensis was detected in all tissues and all developmental stages from vegetative growth to completely differentiated flowers [29]. In Carya cathayensis, CCLFY was strongly expressed in flower buds, but was not detectable in the root and stem. Further detection of buds from short shoots indicated that $C c L F Y$ was expressed increasingly during the first 15 days and subsequently decreased [30].
$L F Y$ overexpression was shown to consume the shoot meristem during flower development, ultimately terminating shoot growth. In general, aspen species flower when they are at least 8-years-old; however, transgenic hybrid aspen plants were found to bloom at 7-months-old following transformation with the Arabidopsis LFY gene [31]. In Fragaria $x$ ananassa, the asexual progeny appeared as an early flowering habit following overexpression of the EjLFY-1 genes [32]. The results of these studies suggest that the role of $L F Y$ in early flowering could be applied to breeding tree species with long juvenile periods.

The construction of prokaryotic expression vectors is a common method used to obtain protein products expressed by target genes in order to study their function. The functions of proteins are largely dependent on their cellular localization, and function in specific tissue parts in cells. Thus, determining the subcellular localization of proteins is a key step in the study of their function [33]. Green fluorescent protein (GFP) is commonly used to study the subcellular localization of proteins [33]. GFP fuses with the target protein and emits green fluorescence under blue light excitation, thus confirming the position of the protein based on the fluorescent signal [34].

Heterodichogamous characteristics are transitional during the evolution of plants from monoecism to dioecism, which appear protandry (the staminate inflorescence sprouts synchronously with leaf spreading, and the pistillate inflorescence sprouts after the pollen mature and disperse) or protogyny (the pistillate inflorescence sprouts synchronously with leaf spreading, and the staminate inflorescence develops slowly at first and then rapidly once the female flowers are pollinated) in a random manner in natural populations [35-38]. Heterodichogamous characteristics have attracted the interest of researchers because of their effects on sexual reproduction, including flowering and pollination [39].

Juglans mandshurica Maxim. is a precious timber and oil tree species with high economic [40-41], nutritional, medicinal [42-49], and collection value. Juglans mandshurica is mainly distributed in the Xiaoxing 'an Mountains, Wanda Mountains, Changbai Mountains, and the eastern mountainous areas of Liaoning, China [50-53], it has also been documented in Russia's Far East, in North Korea, and in Japan [5456], and most of these resources are natural forests. Recently, the natural resources of the species have become endangered due to long-term over-logging and the imbalance of harvesting and breeding. As an endangered and key protected tree species in China [57], the yield and stock volume of J. mandshurica natural secondary forest are lower than those of coniferous timber forest, and the timber yield accounts for less than $1 \%$ of the total timber output in the forest region. However, the market price and demand for $J$. mandshurica timber and fruits has only increased over the years. Thus, a goal for forest management 
and development of the species in northeast China is to utilize natural resources sufficiently and gain maximimum economic benefits.

As a monoecious species, heterodichogamous characteristics were observed when $J$. mandshurica germplasm resources were collected in northeast China. In $J$. mandshurica, the heterodichogamous characteristics and the imbalanced ratios of the pistillate inflorescence and staminate inflorescence (47.7:52.3\% for protandry and 32.1:67.9\% for protogyny, respectively) lead to asynchronous female and male flowers, which greatly affect the efficiency of pollination and fructification, and the subsequent fruit yield. In addition, the long juvenile period (usually 10-15 years from seed germination to flowering and fruiting) of $J$. mandshurica greatly restricts the development of plantation resources, and the fruit and wood dualpurpose forest industry.

To overcome the bottleneck of the long juvenile period and the asynchronous female and male flowers of $J$. mandshurica, and to elucidate the molecular mechanisms underlying flower formation, considering the important roles of $L F Y$ for plant flowering, we cloned the $L F Y$ gene in $J$. mandshurica by homologous cloning and analyzed the expression and subcellular localization of $L F Y$. Our results provide a theoretical foundation and information for improving the fruit yield and quality of $J$. mandshurica, and for the development of genetic improvement strategies, which will have important theoretical and practical significance for production.

\section{Materials and Methods}

\section{Plant Materials}

Three healthy 30-year-old wild $J$. mandshurica were sampled from the Qingyuan region of Liaoning province $\left(\mathrm{N} 41^{\circ} 47-2^{\circ} 28, \mathrm{E} 124^{\circ} 20-125^{\circ} 28\right)$, only three tree samples were selected as there were slight growth trait differences between sampled individuals under such tree age and the wild environmental conditions. Samples of leaf buds, leaves, female buds, male buds, pistils, and stamens were taken every 4-6 days from $2^{\text {nd }}$ April to $21^{\text {st }}$ May, 2017, representing the flower bud dormancy stage (April $2^{\text {nd }}-26^{\text {th }}$ ), sprouting stage ( $30^{\text {th }}$ April to $4^{\text {th }}$ May), and development stage $\left(8^{\text {th }}-21^{\text {st }}\right.$ May). Fruit samples were collected on $4^{\text {th }}$ June, $27^{\text {th }}$ June, $27^{\text {th }}$ July, and $27^{\text {th }}$ August, during the globular, torpedo, cotyledon, and mature embryo stages of zygotic embryogenesis and development, respectively. The samples were wrapped with foil, frozen in liquid nitrogen, and stored in a refrigerator at $-80^{\circ} \mathrm{C}$ for RNA extraction, and subsequent gene cloning and expression.

\section{Molecular Cloning of JmLFY Full-Length}

Total RNA was extracted from leaves using the TIANGEN RNA kit, and cDNA was obtained using the TaKaRa Reverse Transcription System (RR047A) (TaKaRa, Dalian, China) [58].

Based on the mRNA of Juglans regia $L F Y$ protein, the complete coding sequence (CDS) of J. regia $L F Y, C$. cathayensis LFY, and A. thaliana LFY in NCBI (http:// www.ncbi. nlm.nih.gov/), multiple sequence alignments were applied in Clustal X2 to determine conserved sequences in the LFY gene. Primers designed to amplify LFY gene fragments and full-length LFY are listed in Table 1.

The reaction system used to amplify cDNA included cDNA $1 \mu \mathrm{L}$, LFY-F'/F $\left(10 \mu \mathrm{mol}^{-1}\right) 1 \mu \mathrm{L}$, LFY-R'/R $\left(10 \mu \mathrm{mol}^{-1}\right) 1 \mu \mathrm{L}$, LATaq Mix1 $2.5 \mu \mathrm{L}$, and $\mathrm{ddH}_{2} \mathrm{O}$ $9.5 \mu \mathrm{L}$. The reaction procedure was as follows: $94^{\circ} \mathrm{C}$ for $5 \mathrm{~min} ; 35$ cycles of $94^{\circ} \mathrm{C}$ for $40 \mathrm{~s}, 60.6^{\circ} \mathrm{C}$ for $1 \mathrm{~min}$, $72^{\circ} \mathrm{C}$ for $2 \mathrm{~min}$, and $72^{\circ} \mathrm{C}$ for $5 \mathrm{~min}$. The second round of PCR used the same primer, which produced a specific band. The final product was recovered using the MiniBEST Agarose Gel DNA Extraction Kit version 4.0(TaKaRa, Dalian, China), and the purified recovered product was ligated to the pGEM-T cloning vector with T4 DNA ligase using the pGEM-T cloning kit. The vector was then transferred into Escherichia coli DH5acompetent cells. Then, IPTG $16 \mu \mathrm{L}$ and X-gal $40 \mu \mathrm{L}$ were added the competent cells, the mixture was transferred to solid LB medium containing Amp, and the plates were inverted and cultured at $37^{\circ} \mathrm{C}$ for 12-14 h. Subsequently, five to eight single colonies were selected for PCR, and the positive clones were sequenced. The sequencing results were analyzed using NCBI Blast (http://blast.ncbi.nlm.nih.gov/Blast.cgi). Clustal X2.0 was used for multiple sequence alignment. The complete sequence of the product was assembled into the full-length JmLFY cDNA sequence using DNAMAN software and then submitted to GenBank [58-60].

Table 1. Primers used for amplifying full-length and fragment cDNA of $L F Y$ gene in Juglans mandshurica.

\begin{tabular}{|c|c|c|}
\hline Primers & Primer sequence (5'-3') & Usage \\
\hline$L F Y$-F' & ACCACCACCAATGCTCTTGAT & Amplification for cDNA fragment \\
\hline$L F Y$-R' & GMAGYTTKGTGGGWACATACCAA & Amplification for cDNA fragment \\
\hline$L F Y$-F & ATGGATCCCGACCCCTTTACTG & Amplification for cDNA full-length \\
\hline$L F Y-\mathrm{R}$ & GGTGATCACATGCCCCTCTAA & Amplification for cDNA full-length \\
\hline
\end{tabular}




\section{Bioinformatics Analysis of $J m L F Y$}

The physicochemical parameters of the amino acid sequence encoded by $J m L F Y$ were analyzed using BioEdit and ProtParam ExPASy online software. BLAST (http://www.ncbi.nlm.nib.gov/blast) was used to compare homologous sequences, Clustal X2 was used to predict and analyze protein structure, and MAGE4.0 software was used to construct the neighbor joining (NJ) tree by calculating 1000 times repeatedly.

\section{qRT-PCR Analysis}

The expression of $J m L F Y$ in different organs was determined by real-time quantitative PCR (qRT-PCR). Total RNA representing different developmental stages was extracted from young leaves, mature leaves, female buds, male buds, pistils, stamens, and leaf buds by the cetrimonium bromide (CTAB) method. qRTPCR primers were designed based in the sequence of J. mandshurica JmLFY using Primer Premier5.0 (Table 2). Seven common genes that have been used for other species or genera in Juglandaceae were screened for use as reference genes (Table 2). The stability of reference gene expression was analyzed in different $J$. mandshurica tissues using geNorm, NormFinder, and BestKeeper [60-61], and the relatively stable expression gene was used. Fluorescence signals were collected in triplicate for each sample. The relative expression level was calculated using the $2^{-\Delta \Delta \mathrm{Ct}}$ method.

\section{Expression Vector Construction and Prokaryotic Expression}

A total of $100 \mu \mathrm{L}$ bacterial solution of $J m L F Y$ cDNA stored at $-80^{\circ} \mathrm{C}$ was inoculated into $2 \mathrm{~mL} \mathrm{LB}$ liquid medium. The culture was shaken at $37^{\circ} \mathrm{C}$ and
$200 \mathrm{rpm}$ overnight $(12 \mathrm{~h})$, and plasmid was extracted using the Plasmid Small Extraction Kit (TIANGEN). Based on the obtained full-length cDNA sequence of the $J m L F Y$ gene, and the connection requirements of the PBM30 rapid cloning kit, primers were designed to construct the prokaryotic expression vector PBM30-JmLFY, as follows: $L F Y-\mathrm{F} 1,5^{\prime}$ CACCATGGATCCCGACCCCTTTAC-3'; LFY-R1: 5'-GAGGGGCATGTGATCACCC-3'. The plasmid template was amplified by PCR and the products were analyzed by $1 \%$ agarose gel electrophoresis. The target gel band was recovered, purified, and then connected to pBM30 using a pBM30 rapid cloning kit. The recombinant plasmid pBM30-JmLFY was transferred into $E$. coli $\mathrm{DH} 5 \alpha$ competent cells, which were cultured and sequenced to confirm the presence of a successful vector construct. To verify whether the constructed recombinant vector expressed protein, plasmid DNA was extracted from the identified clones, and then transferred into BL21 (DE3) competent cells and cultured on LB solid medium containing kanamycin (50 $\mu \mathrm{g} . \mathrm{mL})$ overnight at $37^{\circ} \mathrm{C}$. Positive colonies were detected by PCR, and then induced by IPTG. The induced products were analyzed by SDS-PAGE polyacrylamide gel electrophoresis to confirm protein expression.

\section{Subcellular Localization of JmLFY Gene}

The PBM30-JmLFY positive clone vector was amplified using a high-fidelity thermostable DNA polymerase, and the product was separated and purified by agarose gel electrophoresis. The target fragment of $J m L F Y$ was fused with the pBM30-GFP fragment, which was cleaved twice by restriction endonuclease, using T4 DNA ligase (Takara). The recombinant pBM30-GFP-JmLFY plasmid DNA was purified using

Table 2. Primers used for real-time quantitation PCR of $J m L F Y$ gene.

\begin{tabular}{|c|c|c|}
\hline Gene symbol & Gene description & Primer pair ( $5^{\prime}$ to $\left.3^{\prime}\right)$ \\
\hline Actin 1 & Caraya illinoensis $\beta$-actin & $\begin{array}{l}\text { F:ACCAACTGGGACGATATGGAGAAGA } \\
\text { R:TACGACCAGAGGCATACAGGGACAA }\end{array}$ \\
\hline Actin 2 & Juglans regia $\beta$-actin & $\begin{array}{l}\text { F: GCTGAACGGGAAATTGTC } \\
\text { R: AGAGATGGCTGGAAGAGG }\end{array}$ \\
\hline Actin 3 & Juglans regia $\beta$-actin & $\begin{array}{l}\text { F:GCCGAACGGGAAATTGTC } \\
\text { R:AGAGATGGCTGGAAGAGG }\end{array}$ \\
\hline $18 \mathrm{~s} 1$ & Juglans regia $18 \mathrm{~S}$ rRNA & $\begin{array}{l}\text { F:GTAGTCATATGCTTGTCTC } \\
\text { R:GTAGTCATATGCTTGTCTC }\end{array}$ \\
\hline $18 \mathrm{~s} 2$ & Juglans regia. 'Xiangling' $18 \mathrm{~S}$ rRNA & $\begin{array}{l}\text { F:GGTCAATCTTCTCGTTCCCTT } \\
\text { R:TCGCATTTCGCTACGTTCTT }\end{array}$ \\
\hline HIS3 & Juglans sigillata,Dode Histone $\mathrm{H} 3$ & $\begin{array}{l}\text { F:GATCGCACAGAGGTTGGTGTC } \\
\text { R:CGTCCGTGAAATTGCACAAGA }\end{array}$ \\
\hline $\mathrm{EF} 1 \alpha$ & Carya carthayensis Elongation factor 1- $\alpha$ & $\begin{array}{c}\text { F:AGGAGCTGGAGAAGGAGCCCA } \\
\text { R:AACAGCAACGGTCTGGCGCA }\end{array}$ \\
\hline qPCR- $L F Y$ & Juglans mandshurica Maxim $L F Y$ gene qPCR fragment & $\begin{array}{l}\text { F:TCCGTTACAAWGAAAGGGTGCT } \\
\text { R:CTTTGGTCGCCATAGCAGCAC }\end{array}$ \\
\hline
\end{tabular}


the DNA Maxiprep kit from TIANGEN. The skin of a fresh onion was disinfection, and the inner skin was removed using sterilized tweezers and spread on sterilized MS medium for 5-7 days' induction until the onion skin was slightly bulging. The onion epidermis was then infected by Agrobacterium containing pBM30-GFP-JmLFY and kanamycin, and then cultured at $28^{\circ} \mathrm{C}$ until $\mathrm{OD}_{600}=0.3$. The cultures were then suspended in an equal volume buffer $(10 \mathrm{mM}$ MES, $800 \mu \mathrm{M}$ acetosyringone, and $10 \mathrm{mM} \mathrm{MgCl}_{2}$ ) for $6-12 \mathrm{~h}$ under a sterile dark state. The onion epidermis was then removed and placed on MS solid medium for 3-4 days, and visualized under a laser scanning confocal microscope (PERKINEIMER UITRAVIEW VOX).

\section{Results}

\section{Cloning of JmLFY Gene}

A specific band of approximately 1300 bp was obtained by PCR amplification using the full-length primer designed by Primer 5.0 and cDNA from young leaves of $J$. mandshurica as a template. The obtained target gene was then sequenced, and the results showed that the sequence was 1297 bp long, with a CDS of 1158 bp.

Homology of the cloned $L F Y$ gene sequence was compared with that of other species in the NCBI database using the BLAST tool. The results showed that $J$. mandshurica $L F Y$ shared 98 and $99 \%$ homology with $C$. cathayensis and $J$. regia $L F Y$, respectively. Notably, J. mandshurica $L F Y$ shared more than $79 \%$ homology, even with some distantly related species, such as Betula platyphylla, Betula luminifera, Castanea henryi, and Prunus mume. This confirms that the flowering related $L F Y$ gene from $J$. mandshurica was successfully cloned, and was subsequently named JmLFY (GenBank: KX364241). The full-length cDNA sequence of the JmLFY gene obtained by sequence analysis using DNAMAN software carries a complete open reading frame (ORF), which can translate a peptide chain consisting of 385 amino acids. In order to categorize the $J m L F Y$ gene and its evolutionary relationship with other $L F Y$ genes, 18 registered amino acid sequences belonging to $L F Y$ genes were selected for cluster analysis.

Clustal X2 was used to compare the amino acid sequences of JmLFY, and MEGA4.0 was used to construct a phylogenetic tree of the 19 homologous amino acid sequences, including $\operatorname{JmLFY}$ (Fig. 1). Cluster analysis showed that $J m L F Y$ clustered together with $C$. cathayensis $C C L F Y$, which then clustered with $J$. regia $(J L F Y)$ as a branch. The branch was clustered to birch $B$. platyphylla $B p L F Y$ and $B$. luminifera $B l L F Y$. It was also closely related to Castanea henryi (ChLFY), Castanea mollissima (CmLFY), Fagus crenata (FCLFY), and Theobroma cacao (TcLFY).

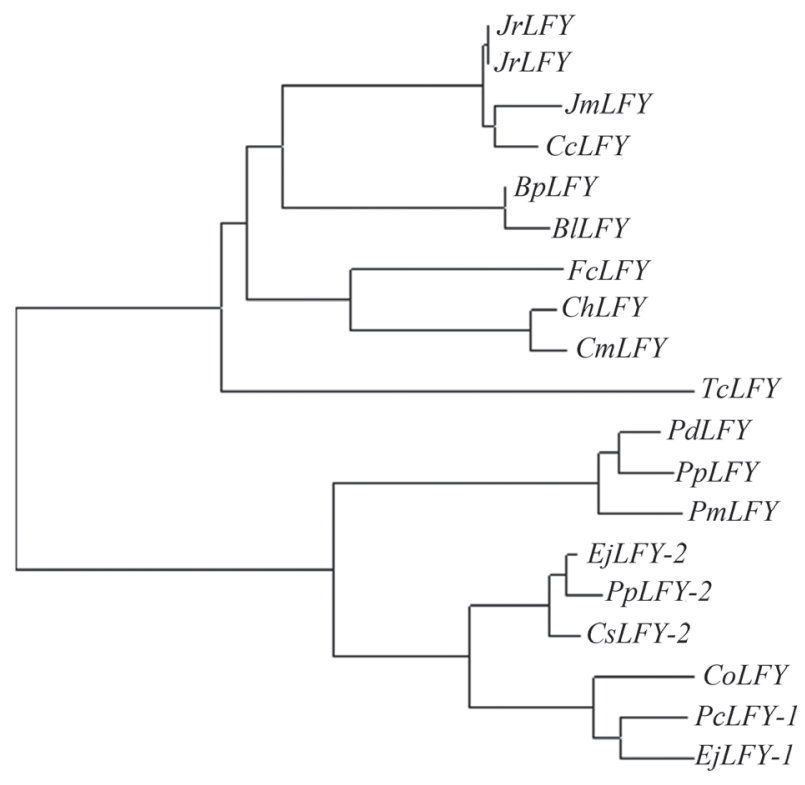

$$
0.02
$$

Fig. 1. Cluster analysis of the amino acids sequences encoded by $J m L F Y$ and other $L F Y$ homologous genes. Species resources of the LFY used are Juglans regia (Jrlfy, GU194836.4; Jrlfy JF520778.1); Carya cathayensis (CcLFY, DQ989225.1); Betula platyphylla (BpLFY, KP693587.1); Betula luminifera, (BILFY, KP970616.1); Fagus crenata (FcLFY, AB674454.1); Castanea henryi (Chlfy, JQ825167.1); Castanea mollissima (Cmlfy, DQ270548.1); Theobroma cacao (TcLFY, XM_007038099.1) ; Prunus dulcis (PdLFY, AY947465.1); Prunus persica (PpLFY, EF175869.1); Prunus mume (PmLFY, KT803848.1); Eriobotrya japonica (EjLFY-2, AB162039.19); Pyrus pyrifolia, (PpLFY-2, AB162035.1); Chaenomeles sinensis (CsLFY, AB162038.1); Cydonia oblonga (CoLFY-1, AB162031.1); Pyrus communis, (PcLFY-1, AB162030.1); Eriobotrya japonica (EjLFY-1, AB162033.1).

Lower levels of homology were found when comparing $J$. mandshurica with Rosaceae species (nine LFYs). However, when the amino acid sequence encoded by the $L F Y$ gene was compared with that encoded by $J m L F Y$, homology exceeded $79 \%$, indicating that LFY is highly homologous among plant species.

The amino acid sequence encoded by JmLFY contained an N-terminal proline-enriched region, a central acid region, a leucine zipper structure, and conserved $\mathrm{N}$ - and C-terminal regions (Fig. 2). These results confirm that the full-length cDNA sequence of the $L F Y$ gene was successfully cloned, which is related to flowering in $J$. mandshurica.

\section{Selection and Stability Verification of Candidate Internal Reference Genes}

The Ct value of each internal reference gene differed among samples (young leaves, mature leaves, female buds, male buds, pistils, stamens, and leaf buds) (Fig. 3). This wide range of CT values indicated that expression of internal reference genes is unstable, making them 


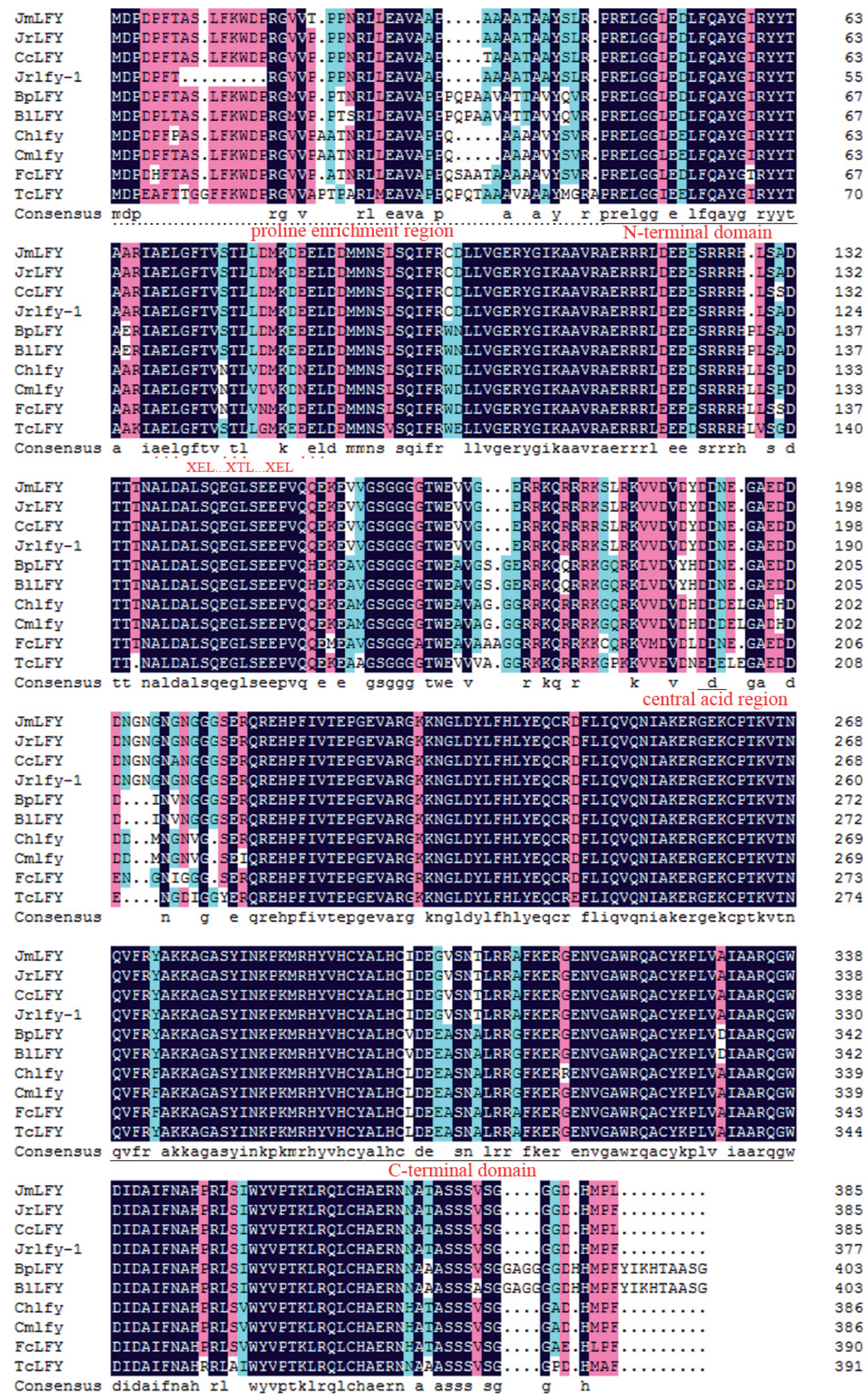

Fig. 2. Alignment of amino acids sequences encoded by $J m L F Y$ and other $L F Y$ homologous genes. The ellipsis meant the missing part of the sequences compared to others. 


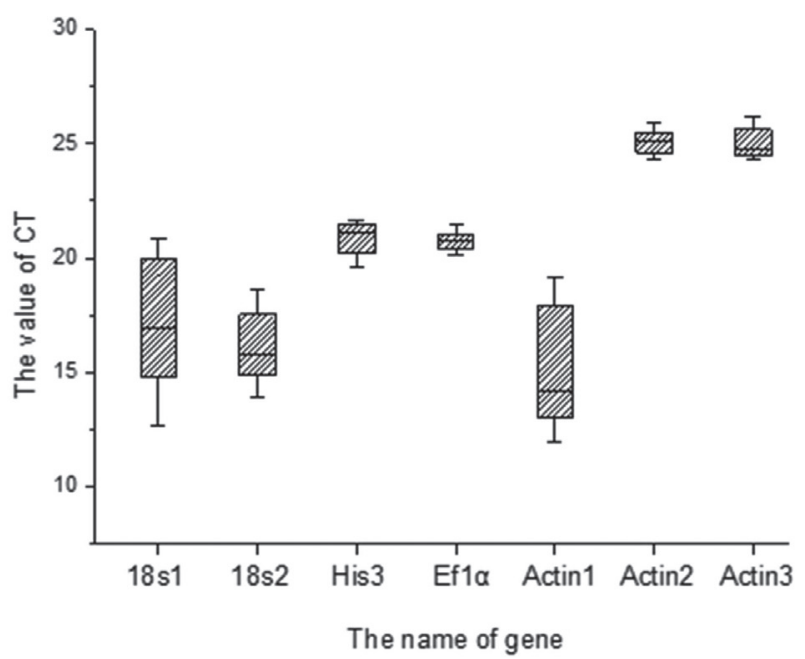

Fig. 3. Ct values of the candidate reference genes for RT-qPCR. A line across the box represented the median, and the " $T$ " line under and below represented the maximum and minimum.

unsuitable for use as reference genes in this study. Thus, considering the $\mathrm{Ct}$ values and the results obtained with geNorm, NormFinder, and BestKeeper software (data not shown), EF1 $\alpha$ was selected as a stably expressed internal reference gene for further study.

\section{qRT-PCR Analysis}

Expression of the $J m L F Y$ gene was relatively stable during the male flower bud dormant period $\left(2^{\text {nd }}-26^{\text {th }}\right.$ April), with relative expression levels less than 1.5 (Fig. 3). However, following the sprouting stage $\left(30^{\text {th }}\right.$ April) of staminate inflorescences, expression of the $J m L F Y$ gene increased, peaking on May 4 and 17, which represented the later sprouting stage (or the predevelopment stage) and the mid development stage, respectively, after which expression decreased sharply on May 21 (Fig. 3). These results indicated that the $J m L F Y$ gene plays an important role before the early development stage of staminate inflorescence and in the mid developmental stage of the flower (such as anther formation and pollen dispersal, based on phenological observations of flower organs for $J$. mandshurica in 2017). When the male flowers withered (May 21), $J m L F Y$ expression decreased sharply.

The expression pattern of $J m L F Y$ was similar during the developmental stage of the pistillate inflorescence. Expression was relatively stable during the dormant stage $\left(2^{\text {nd }}-26^{\text {th }}\right.$ April), and then increased markedly from the pistillate inflorescence sprouting stage to flower development (30 $0^{\text {th }}$ April to $13^{\text {th }}$ May) (Fig. 3). Then, the expression of JmLFY in pistillate inflorescences decreased sharply (Fig. 3). These results suggest that $J m L F Y$ has an important role in pistillate inflorescence sprouting and flower development.

The expression of $J m L F Y$ in pistils on the same day (24 $4^{\text {th }}$ May) at different development stages was also analyzed. Higher expression was observed in

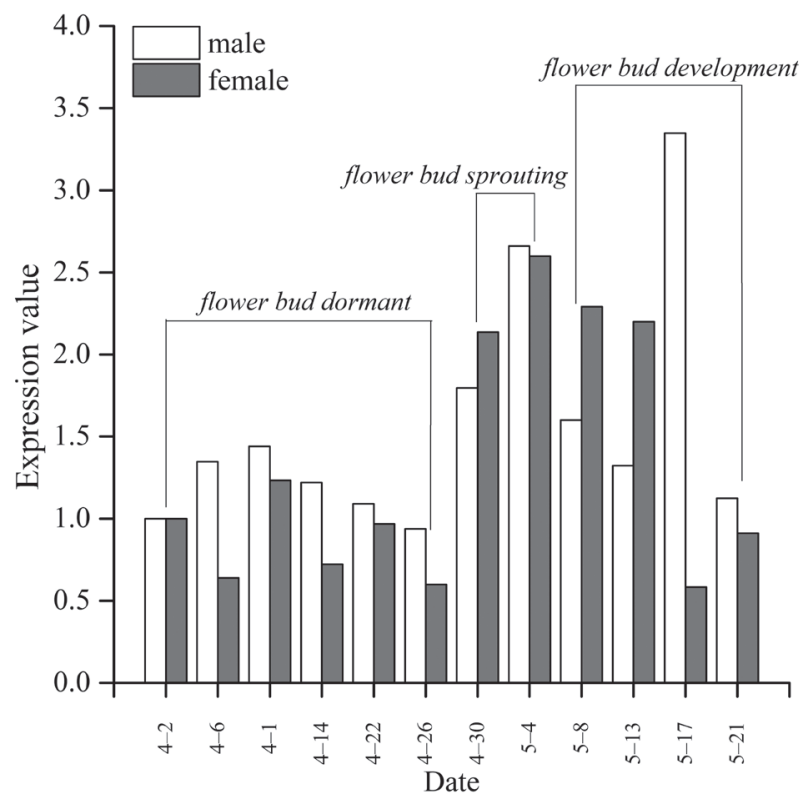

Fig. 4. Relative expression of JmLFY gene in male and female organs at different development stage.

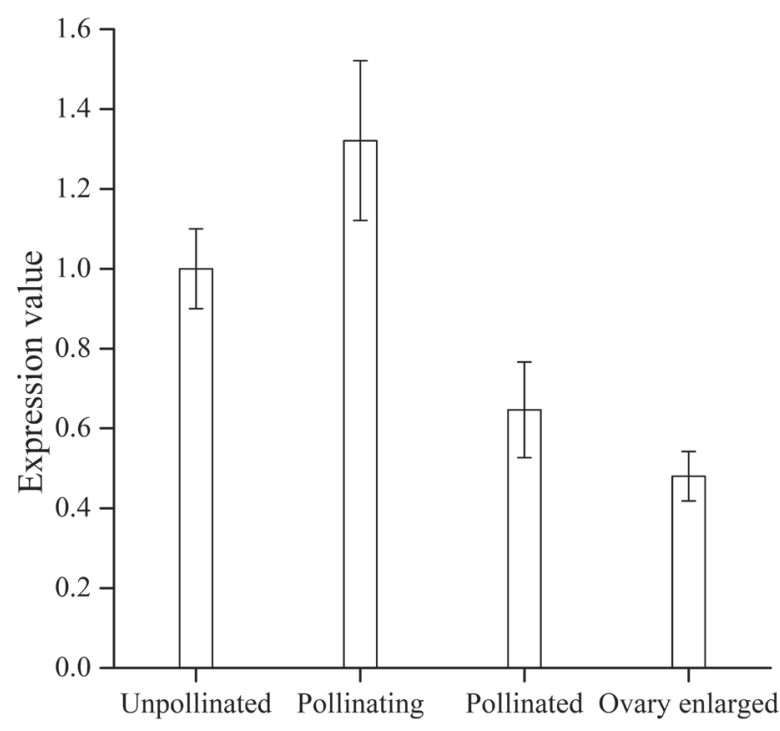

Status

Fig. 5. Relative expression of $J m L F Y$ gene in pistils experienced different development events on the same day (May $24^{\text {th }}$ ).

unpollinated pistils and pollinating pistils, while lower expression was observed in pollinated pistils and pistils with enlarged ovaries (Fig. 4). Analysis of JmLFY in zygotic embryos at different developmental stages revealed that expression was lower during the globular and torpedo embryo stages $\left(4^{\text {th }}-27^{\text {th }}\right.$ June) of zygotic embryogenesis compared with the cotyledon embryo stage (27 ${ }^{\text {th }}$ July and $27^{\text {th }}$ August; Fig. 5). These results indicate that the $J m L F Y$ gene plays an important role in pollination and in the late stage of zygotic embryo development. 


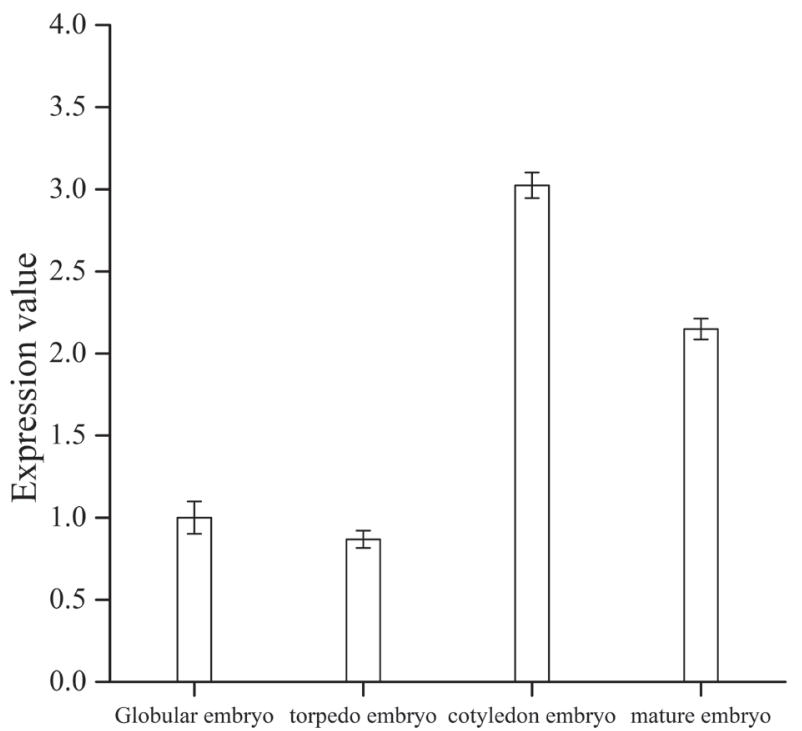

Development stage of embryo

Fig. 6. Relative expression of $J m L F Y$ gene in zygotic embryos at different development stage.

The $J m L F Y$ gene was also expressed in leaf buds, and expression was stable from April 2-30 before increasing on May 4 and 8 , which is consistent with the development of staminate and pistillate inflorescences (Fig. 6).

\section{Prokaryotic Expression of $J m L F Y$ Gene}

A prokaryotic expression vector was constructed using the pBM30 rapid cloning kit. Sequencing of positive colonies $(1155 \mathrm{bp})$ confirmed that $J m L F Y$ was successfully included in the carrier pBM30. To verify protein expression driven by the recombinant vector, plasmid DNA was extracted from the identified clones. This DNA was then transferred to BL21 (DE3) competent cells and cultured on LB solid culture medium containing kanamycin $\left(50 \mu \mathrm{g} \cdot \mathrm{mL}^{-1}\right)$ overnight at $37^{\circ} \mathrm{C}$. Positive colonies were detected by PCR, and then induced with IPTG. Following induction, products were detected by SDS-PAGE polyacrylamide gel electrophoresis. The results revealed protein bands of approximately $50 \mathrm{kDa}$ in lanes containing bacterial liquid that was treated with IPTG, while no such band was found in the lane containing bacterial culture that was not treated with IPTG (Fig. 7). These results indicated that the pBM30-JmLFY recombinant vector could express protein successfully.

\section{Subcellular Localization of $J m L F Y$ Gene}

To determine the subcellular localization of the $J m L F Y$ protein, the JmLFY gene was transiently expressed in onion epidermal cells and imaged under a laser confocal microscope by constructing a fusion vector comprising $J m L F Y$ and enhanced green

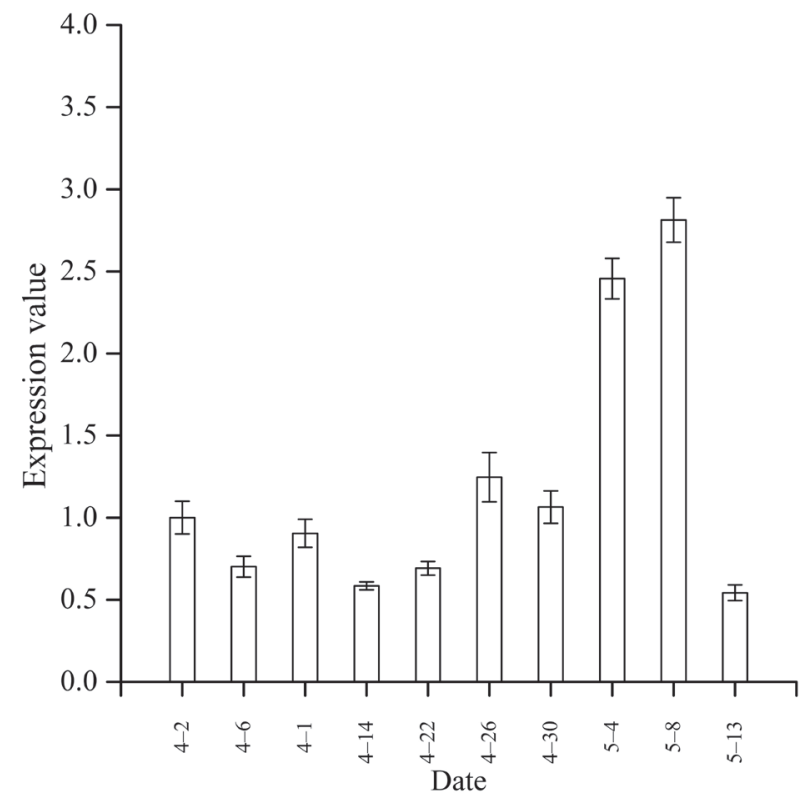

Fig. 7. Relative expression of $J m L F Y$ gene in leave bud at different development stage.

fluorescent protein pBM30-GFP. Detection of the pBM30-GFP-LFY fusion vector using a dual-turntable laser confocal real-time imaging analyzer, revealed that the $J m L F Y$ protein was expressed in the nucleus and cytoplasm (Fig. 8 and Fig. 9).

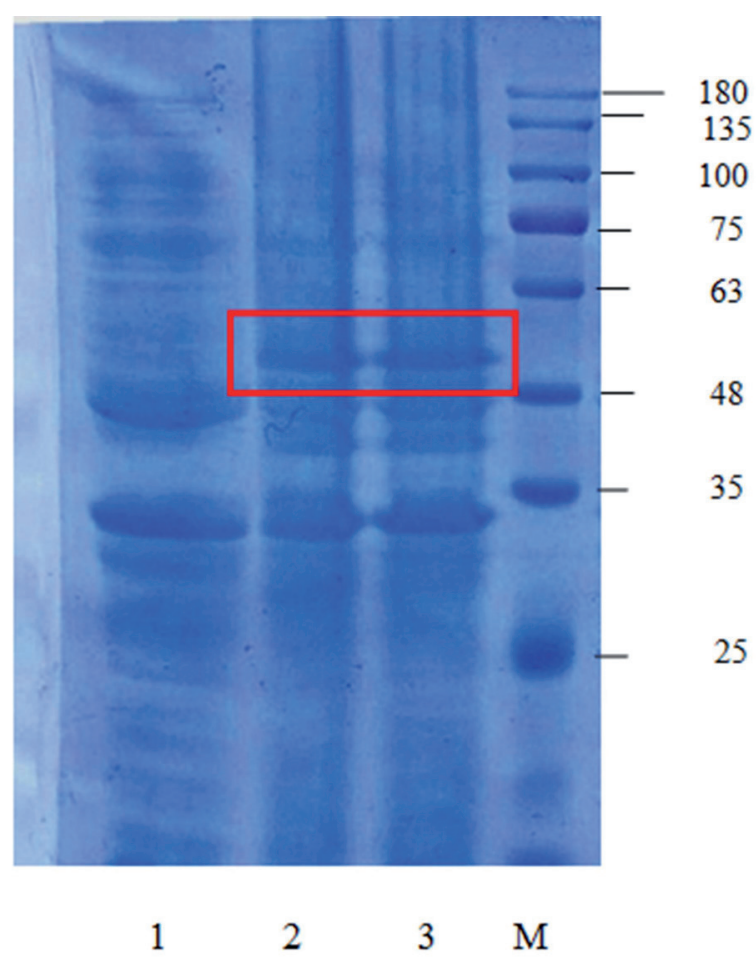

Fig. 8. SDS polyacrylamide gel electrophoresis. Lane 1, treated without IPTG; lane 2-3, treated with IPTG. 

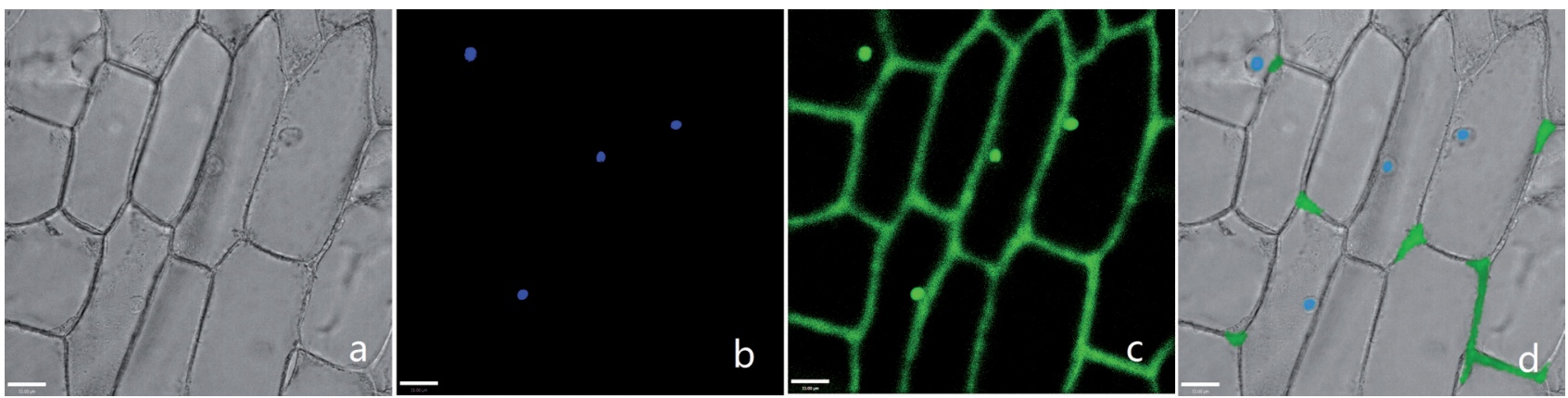

Fig. 9. Subcellular Localization of the pBM30-GFP-JmLFY. a) bright field; b) nucleus stained by DAPI (excitation at $405 \mathrm{~nm}$ ); c) subcellular localization represents fluorescence signal (excitation at $488 \mathrm{~nm}$ ); d merged image of panels.

\section{Discussion}

Dioecy is a transition type in the evolution process of plants from monoecy to dioecy. In the evolution process of flowering plants from monoecy to dioecy, the reproductive system evolves through the special alienation of male and female flowers to form two mating type groups, namely, female-premorphic and male-premorphic [62-66]; Because the hermaphroditism of plants will directly affect the sexual reproduction process such as flowering and pollination, the reproductive characteristics of plants have aroused widespread interest of researchers at home and abroad [67-69]. It is very important to study the spatiotemporal expression of male and female flowers in higher plants at the molecular level to reveal the regulation mechanism of sex expression in higher plants. At present, research in this field mainly focuses on the cloning and expression analysis of flower development related genes. Through deep sequencing [68-70]. In conclusion, the expression pattern of flower development-related genes may play an important role in the regulation of sex differentiation. In all flowering plants, LFY gene is an important gene in the regulation of flower organs and one of the earliest identified flowering genes. It is a highly conserved plant-specific transcription factor [58]. In this study, BLAST sequence alignment showed that LFY homologous genes cloned from Juglans mandshurica showed high similarity to LFY gene sequences of plants such as Upland cotton.The amino acid sequence encoded by the flower-related jMLFY gene of Juglans mandshurica was compared with that of other species. LFY gene also had proline rich region at the N-terminal, central acid region, leucine zipper structure, and conserved regions at the N-terminal and $\mathrm{C}$-terminal. These amino acid structures are consistent with those of LFY gene studied by previous researchers [60], which are sufficient to prove that we have successfully cloned the full-length cDNA sequence of LFY gene related to flowering of Juglans mandshurica. These results not only indicate the high homology of these LFY/ Flo gene families, but also suggest that these proteins may have similar functions. Both the PMLFY1 gene transducing plum to Arabidopsis thaliana [52] and the ACLFY gene transplanting onion to Arabidopsis thaliana can promote the early flowering of Arabidopsis thaliana, which proves that the over expression of LFY gene can promote the flowering of plants, showing the significant role of LFY gene in promoting the flowering of plants. It is also more direct proof that the flowerrelated LFY gene can promote the early flowering of plants. According to the high homology of LFY/ Flo family genes, it could be predicted that the same result could be obtained if JMLFY was transferred into Arabidopsis thaliana. It can be used as an experimental direction to verify the function of JMLFY gene.

Flowering affects the reproductive success of plants and is an important part of the life cycle of plants. The transformation of plants from vegetative development stage to reproductive development stage is regulated by a variety of complex molecular networks, in which many genes are involved, such as LFY, CO, FT, AP1, TFL1, etc. These flowering-related genes regulate and restrict each other [53]. Among these regulatory genes, LFY gene is a key gene related to flower formation. Studies have shown that many different plants contain LFY gene related to flower formation, and LFY gene is expressed to varying degrees in roots, stems, leaves and other organs except in flower organs, and with the change of time. The expression level of LFY gene in different organs also varies with it, showing a certain period of time [49]. Therefore, the study of the expression characteristics of LFY gene is helpful to find the expression rules of LFY gene, and further prove the relationship between LFY gene and flower formation, which plays an important role in the study of the function of LFY gene. In this study, we selected female flower buds, male flower buds, pistils, stamens, leaf buds and fruits of different developmental stages of Juglans mandshurica for real-time fluorescence quantitative expression analysis of JMLFY gene. The results showed that JMLFY gene was expressed in different organs and tissues of Juglans mandshurica, and there were differences in the expression levels of the same organ at different stages. The expression level of JMLFY gene in floral related organs was significantly higher than that in non-floral organs. These results indicate that JMLFY gene is indeed 
a key gene related to flower formation, and its regulatory mechanism in flower formation pathway and its role in non-flower organs deserve further study. Therefore, the prokaryotic expression vector of JMLFY gene in Juglans mandshurica was constructed, and the protein products were obtained. The protein structure of the expressed protein products was analyzed, which laid a foundation for exploring the function and regulation of JMLFY related to flowering at the protein level. Protein function is closely related to its localization in cells. Proteins can only play their functions when they mature and must be allocated to specific parts of the cell tissue. The subcellular localization information of proteins reflects their real biological functions. Subcellular localization is a key step in the study of protein function, and green fluorescent protein gene (GFP) is currently the most widely used [38]. In this study, in order to further determine the subcellular localization of JMLFY protein, JMLFY was fused with the enhanced green fluorescent protein of PBM30-GFP to construct the fusion expression vector PBM30-GFPLFY, which was introduced into onion epidermal cells by gene gun. It was found that the fusion expression vector of JMLFY-GFP could see green fluorescence in the nucleus, which further proved that the protein had the general characteristics of transcription factor. This result is consistent with the reported nuclear localization of LFY gene in upland cotton, alfalfa and carrot [32]. This suggests that the homologous LFY gene has similar functions and functions in regulating flower initiation

$L F Y$ is crucial for plant flowering, and its expression differs between organs, such as the root, stem, leaf, and flower, and between developmental stages. In the present study, the $J m L F Y$ gene was cloned successfully and its expression was analyzed in different organs and at different developmental stages. The homology with other species was more than $80 \%$. Additionally, the structure of the amino acid sequence was similar to that reported in other species, implying that the function of $J m L F Y$ is similar to that of $L F Y$ in other species. The high homology of $L F Y / F L O$ family genes suggests that the same results will be obtained for $J m L F Y$, which may be used to verify the function of $J m L F Y$ in future studies. Wang et al. (2014) studied the expression of $C c L F Y$ in different organs and in different developmental stages of $C$. cathayensis female flower buds [37]. The results revealed that $C C L F Y$ was highly expressed in both immature leaves and flower buds, and the morphological expression was asynchronous to gene expression. Similar results were found in our study; we showed that $J m L F Y$ is expressed in different organs and that the expression level differs in the same organ at different development stages. JmLFY expression increased before the early development stage of the staminate inflorescence, anther formation and pollen dispersal stage, pistillate inflorescence sprouting and flower development stage, and the pollination and late stage of zygotic embryo development.

\section{Conclusions}

In this study, we successfully cloned the cDNA sequence of the $L F Y$ gene in J. mandshurica. The CDS sequence was 1158 bp long and encoded 385 amino acids. Homology analysis of the nucleotide and amino acid sequences encoded by $J m L F Y$ revealed high homology between $J m L F Y$ and $L F Y$ genes from other species, particularly in related species. This confirmed that $L F Y$ was indeed obtained in our study. The gene was named JmLFY and the full-length CDS was submitted to the NCBI database (GenBank: KX364241). qRT-PCR analyses revealed that the JmLFY gene is expressed constitutively in male and female organs of $J$. mandshurica. The expression of JmLFY increased significantly during flower bud sprouting, flower induction, early fruit formation, and fruit maturation. The relative expression of $J m L F Y$ also increased in leaf buds during the flower bud sprouting stage. A vector (pBM30-JmLFY) was successfully constructed for the prokaryotic expression of $J m L F Y$, which was transformed into the BL21 (DE3) competent state and induced by IPTG. The product was detected by SDSPAGE polyacrylamide gel electrophoresis, and the results revealed a protein with the expected size of $\sim 50$ $\mathrm{kDa}$, confirming that the $\mathrm{pBM} 30-J m L F Y$ vector could express protein. Subcellular localization of JmLFY protein revealed that it is located in both the nucleus and cytoplasm, which differs from previous reports. Our results demonstrate that $J m L F Y$ was cloned successfully. In addition, we verified the high level of structural homology, and similarity of function and expression of $J m L F Y$ with $L F Y$ genes in other species.

\section{Acknowledgments}

This work is supported by funds from the National Key Research and Development Plan of China" 2017YFD0600600", and Foundation for State Major Research Project of China"2017YFD0600605".

\section{References}

1. BOUCHÉ F., LOBET G., TOCQUIN P., PERILLEUX C. FLOR-ID: an interactive database of flowering-time gene networks in Arabidopsis thaliana. Nucleic Acids Research, 44, 1167, 2016.

2. CHO L.H., YOON J., AN G. The control of flowering time by environmental factors. Plant Journal, 90, 708, 2017.

3. SHIM J.S., KUBOTA A., IMAIZUMI T. Circadian Clock and Photoperiodic Flowering in Arabidopsis: CONSTANS Is a Hub for Signal Integration. Plant Physiology, 173, 5, 2017.

4. SUN S., VERDÚM. Evolutionary correlation of heterodichogamy and floral longevity. Evolutionary Ecology, 30, 1023, 2016.

5. MOON J., LEE H., KIM M., LEE I. Analysis of flowering pathway integrators in Arabidopsis. Plant Cell Physiology, 46, 292, 2005. 
6. LIU C., THONG Z., YU H. Coming into bloom: the specification of floral meristems. Development, 136 (20), 3379, 2009.

7. XU J., ZHONG X., ZHANG Q., LI H. Overexpression of the GmGAL2 gene accelerates flowering in Arabidopsis. Plant Molecular Biology Reporter, 28, 704, 2010.

8. MA G., NING G., ZHANG W., ZHAN J., LV H., BAO M. Overexpression of Petunia SOC1-like gene FBP21 in tobacco promotes flowering without decreasing flower or fruit quantity. Plant Molecular Biology Reporter, 29, 573, 2011.

9. CHANG L., WU L., CHEN Y., KU L., YANG S., ZHANG S., WANG X., WEI X. Expression and functional analysis of the ZCN1 (ZmTFL1) gene, a TERMINAL FLOWER 1 homologue that regulates the vegetative to reproductive transition in maize. Plant Molecular Biology Reporter, 30, 55, 2012.

10. SEARLE I., HE Y., TURCK F., VINCENT C., FORNARA F., KRÖBER S., AMASINO R.A., COUPLAND G. The transcription factor FLC confers a flowering response to vernalization by repressing meristem competence and systemic signaling in Arabidopsis. Genes and Development, 20, 898, 2006.

11. AMIN H., MAJID R., HOSSEIN R. Flowering in Persian walnut: patterns of gene expression during flower development. BMC Plant Biology, 20, 136, 2020.

12. DU N., PIJUT P.M. Isolation and characterization of an AGAMOUS homolog from Fraxinus pennsylvanica. Plant Molecular Biology Reporter, 28, 344, 2010.

13. LIU X., ANDERSON J.M., PIJUT P.M. Cloning and characterization of Prunus serotina AGAMOUS, a putative flower homeotic gene. Plant Molecular Biology Reporter, 28, 193, 2010.

14. HOU J.H., GAO Z.H., ZHANG Z., CHEN S.M., ANDO T., ZHANG J.Y., WANG X.W. Isolation and characterization of an AGAMOUS homologue PmAG from the Japanese apricot (Prunus mume Sieb. et Zucc.). Plant Molecular Biology Reporter, 29, 473, 2011.

15. LI H., LIU F., LIU G., WANG S., GUO X.H., JING J. Molecular cloning and expression analysis of 13 MADSBox genes in Betula platyphylla. Plant Molecular Biology Reporter, 30, 149, 2012.

16. QI X., TOWNSLEY B., AGUILAR-MARTÍNEZ J.A., YIN L., GAO X., HOU L., GAO M., LI M. Cloning and characterization of the $L F Y$ homologue from Chinese cabbage (Brassica rapa subsp. pekinensis). Horticulture, Environment, and Biotechnology, 56, 821, 2015.

17. ZHENG J.W., HUANG J.Q., HUANG Y.J., CHEN F.F., ZHENG B.S. Cloning and characterization of a homologue of the FLORICAULA/LEAFY Gene in hickory (Carya cathayensis Sarg.). Plant Molecular Biology Reporter, 30, 794, 2012.

18. LIU Y.X., ZHAO Q., MENG N., SONG H., LI C., HU G., WU J., LIN S., ZHANG Z. Over-expression of EjLFY-1 leads to an early flowering habit in strawberry (Fragariax ananassa) and Its Asexual Progeny. Frontiers in Plant Science, 8, 1, 2017.

19. HUH W.K., FALVO J.V., GERKE L.C., CARROLL A.S., HOWSON R.W., WEISSMAN J.S., O'SHEA E.K. Global analysis of protein localization in budding yeast. Nature, 425, 686, 2003.

20. XING H.R., LIU L.J., LIU G.Z. Advancement of protein subcellular localization in plants. North China Agricultural Journal, 21 (S2), 1, 2006.

21. GLEISER G., VERDU M., SEGARRA-MORAGUES J.G., GONZ'ALEZ-MART'INEZ S.C., PANNELL J.R.
Disassortative mating, sexual specialization, and the evolution of gender dimorphism in heterodichogamous Acer opalus. Evolution, 62, 1676, 2008.

22. TEICHERT H., DÖTTERL S., GOTTSBERGER G. Heterodichogamy and nitidulid beetle pollination in Anaxagorea prinoides, an early divergent Annonaceae. Plant Systematics and Evolution, 291, 25, 2011.

23. WANG X.M., ZHANG P., DU Q.G., HE H.X., ZHAO L.I., REN Y., ENDRESS P.K. Heterodichogamy in Kingdonia (Circaeasteraceae, Ranunculales). Annals of botany, 109, 1125, 2012.

24. FUKUHARA T., TOKUMARU S. Inflorescence dimorphism, heterodichogamy and thrips pollination in Platycarya strobilacea (Juglandaceae). Annals of Botany, 113, 467, 2014.

25. WANG D.N., MOU C.C., GAO Z., FENG F.J. ISSR analysis of genetic diversity of Juglans mandshurica Maxim populations. Nonwood Forest Research, 29, 22, 2011.

26. WANG K., ZHU J.J., YU L.Z., SUN Y.R., ZHANG J.X. Effects of light environment on Juglans mandshurica seedlings growth and photosynthesis. Chinese Journal of Applied Ecology, 21, 821, 2010.

27. ZHUANG H., ZHANG T., GAO X.X., WANG Y., ZHANG Q. De novo assembly and characterization of the leaf, bud, and fruit transcriptome from the vulnerable tree Juglans mandshurica for the development of 20 new microsatellite markers using Illumina sequencing. Molecuar Genetics Genomics, 291, 849, 2016.

28. HASAN T.N., GRACE B.L., SHAFI G., AL-HAZZANI A.A., ALSHATWI A.A. Anti-proliferative effects of organic extracts from root bark of Juglans regia L. (RBJR) on MDA-MB-231 human breast cancer cells: role of Bcl-2/ Bax, caspases and Tp53. Asian Pacific Journal of Cancer Prevention, 12, 525, 2011.

29. SALIMI M., MAJD A., SEPAHDAR Z., AZADMANESH K., IRIAN S., ARDESTANIYAN M.H., HEDAYATI M.H., RASTKARI N. Cytotoxicity effects of various Juglans regia (walnut) leaf extracts in human cancer cell lines. Pharmaceutical Biology, 50, 1416, 2012.

30. ZHAO M.H., JIANG Z.T., LIU T., LI R. Flavonoids in Juglans regia L. leaves and evaluation of in vitro antioxidant activity via intracellular and chemical methods. Scientific World Journal, 2014, 1, 2014.

31. GUO L.N., ZHANG R. CUI T., DONG W., HUO J.H., WANG W.M. Identification of new naphthalenones from Juglans mandshurica and evaluation of their anticancer activities. Chinese Journal of Natural Medicines, 13, 707, 2015.

32. ZAN Z.H., GAO Y.M., SUN M.L. Extraction and antioxidant activity of tannic in Juglans mandshurica Maxim. Bulletin of Botanical Research, 35, 431, 2015.

33. ZHANG W., LI Y., LUO J., LU X., CHEN M., ZHU W., JIANG Y. Juglone inhibits proliferation and induces apoptosis of human cervical squamous cancer Si Ha cells. Chinese Journal of Cellular and Molecular Immunology, 31, 186. 2015.

34. HU Z., ZHANG T., GAO X.X., WANG Y., ZHANG Q. De novo assembly and characterization of the leaf, bud, and fruit transcriptome from the vulnerable tree Juglans mandshurica for the development of 20 new microsatellite markers using illumina sequencing. Molecular Genetics and Genomics, 291, 849, 2016.

35. MACHIDA K., YOGIASHI Y., MATSUDA S., SUZUKI A., KIKUCHI M. A new phenolic glycoside syringate from 
the bark of Juglans mandshurica Maxim. var. sieboldiana Makino. Journal of Natural Medicines, 63, 220. 2009.

36. ZHANG S.Y., DU F.G. The research situation and conservation strategies of Juglans mandshuria. Northern Horticulture, 9, 199, 2014

37. CHEN G.P., CHENG S.S., CONG M.Y., LIU J., SHI F.C. Effects of litter decomposition on soil nutrients in three broad-leaved forests. Chinese Journal of Ecology, 33, 874, 2014.

38. WANG R., WANG S., XIA Y., TU M., ZHANG L. Antitumor effects and immune regulation activities of a purified polysaccharide extracted from Juglan regia. International Journal of Biological Macromolecules, 72, 771, 2015.

39. ZHOU Y.Y., SONG H.J., GUO S., WANG Y., GAO H.R., ZHANG X.J., SUN Y.P., LIU Y., YANG B.Y., KUANG H.X. A new triterpene from the green walnut husks of Juglans mandshurica Maxim. Journal of Natural Medicines, 73, 800, 2019.

40. WANG Z.J., HUANG J.Q., HUANG Y.J., CHEN F.F., ZHENG B.S. Cloning and characterization of a homologue of the floricaula/leafy gene in hickory (Carya cathayensissarg). Plant Molecular Biology Reporter, 30, 794, 2012.

41. HUANG Y.J., LIU L.L., HUANG J.Q. WANG Z.J., CHEN F.F., ZHANG Q.X., ZHENG B.S., CHEN M. Use of transcriptome sequencing to understand the pistillate flowering in hickory (Carya cathayensis Sarg.). BMC Genomics, 14, 691, 2013.

42. ANDERSEN C.L., JENSEN J.L., ØRNTOFT T.F. Normalization of real-time quantitative reverse transcription-pcr data: a model-based variance estimation approach to identify genes suited for normalization, applied to bladder and colon cancer data sets. Cancer Research, 64, 5245, 2004.

43. FUKUHARA T., TOKUMARU S. Inflorescence dimorphism, heterodichogamy and thrips pollination in Platycarya strobilacea (Juglandaceae). Annals of Botany, 113, 467, 2014.

44. RENNER S.S. The relative and absolute frequencies of angiosperm sexual systems: dioecy, monoecy, gynodioecy, and an updated online database. Annals of Botany, 101, 1588, 2014

45. SUN S., VERDU M. Evolutionary correlation of heterodichogamy and floral longevity. Evolutionary Ecology, 3, 1, 2016.

46. KANNO A., HIENUKI H., ITO T. The structure and expression of SEPALLATA-like genes in Asparagus species (Asparagaceae). Sex Plant Reprod, 19, 133, 2006.

47. HU J., JIN Q., MA Y.P. AfLFY, a LEAFY homolog in Argyranthemum frutescens, controls flowering time and leaf development. Scientific Reports 10, 1616. 2020.

48. GAO B., CHEN M.X., LI X.S., ZHANG J.H. Ancient duplications and grass-specific transposition influenced the evolution of LEAFY transcription. Communication Biology 2, 237, 2019.

49. LI J., FAN S.L., SONG M.Z., PANG C.Y., WEI H.L., LI W., MA J.H., WEI J.H., JING J.G. YU S.X. Cloning and characterization of a FLO/LFY ortholog in Gossypium hirsutum L. Plant Cell Reports, 32, 1675, 2013.

50. LU S.J., LI Z.N., ZHANG J.Q., YI S.S., LIU L., BAO M.Z., LIU G.F., Isolation and expression analysis of a LEAFY/ FLORICAULA homolog and its promoter from London plane (Platanus acerifolia Willd.). Plant Cell Reports, 31, 1851, 2012
51. AHMAD S., LI Y.S., YANG Y.J., ZHOU Y.Z., ZHAO K., ZHANG Q.X. Isolation, functional characterization and evolutionary study of LFY1 gene in Prunus mume. Plant Cell, Tissue and Organ Culture, 136, 523, 2019.

52. ZHU Y., KLASFELD S., JEONG C.W., JIN R., GOTO K., YAMAGUCHI N., WAGNER D. TERMINAL FLOWER 1-FD complex target genes and competition with FLOWERING LOCUS T. Nature Communications, 11, 5118, 2020.

53. YANG C.C., YE Y.Y., SONG C., CHEN D., JIANG B.W., WANG Y. Cloning and Functional identification of the AcLFY gene in Allium cepa. Biochemical and Biophysical Research Communications, 473, 1100, 2016.

54. HU Z., ZHANG T., GAO X.X., WANG Y., ZHANG Q., ZHOU H.J., ZHAO G.F., WANG M.L., WOESTE K.E., ZHAO P. De novo assembly and characterization of the leaf, bud, and fruit transcriptome from the vulnerable tree Juglans mandshurica for the development of 20 new microsatellite markers using illumina sequencing. Molecular Genetics and Genomic Medicine. 291, 849, 2016.

55. ZHANG L.J., LU X., ZHOU Q., DENG J.F. Morphological variability between geographical provenances of walnut fruit (Juglans mandshurica) in the eastern Liaoning Province, P.R. China. Polish Journal of Environmental Studies, 30, 1, 2021.

56. ZHANG L.J., ZHOU Y.C., LU X.J., ZHOU Q., YANG Y.C., LIU C.P., DENG J.F. Selection of Superior Trees of Juglans Mandshurica in Eastern Liaoning and Effects of Environmental Factors on Its Growth. Fresenius Environmental Bulletin, 30, 6434, 2021.

57. HU J., JIN Q., MA Y. AfLFY, a LEAFY homolog in Argyranthemum frutescens, controls fowering time and leaf development. Scientific Reports, 10, 1616, 2020.

58. SHARMA B., MEADERS C., WOLFE D., HOLAPPA L., WALCHER-CHEVILLET C., KRAMER E.M. Homologs of LEAFY and UNUSUAL FLORAL ORGANS Promote the Transition From Inflorescence to Floral Meristem Identity in the Cymose Aquilegia coerulea. Frontiers in Plant Science, 10, 1218, 2019.

59. JANG S.H. Functional Characterization of PhapLEAFY, a FLORICAULA/LEAFY ortholog in Phalaenopsis Aphrodite. Plant Cell Physiology 56, 2234, 2015.

60. ZHANG C.S., ZHANG H.W., ZHAN Z.X., YI L. Molecular cloning, expression analysis and subcellular localization of LEAFY in carrot (Daucus carota L.). Molecular Breeding, 36, 89, 2016.

61. ZHANG T., CHAO Y., KANG J., DING W., YANG Q. Molecular cloning and characterization of a gene regulating flowering time from Alfalfa (Medicago sativa L.). Molecular Biology Reports, 40, 597, 2013.

62. ZHANG Q.L., ZHU Q.H., LIAO X., WANG X.Q., CHEN T., XU H.T., WANG J., YUAN M.L., CHEN Y.J. Selection of reliable reference genes for normalization of quantitative rt-pcr from different developmental stages and tissues in amphioxus. Scientific Reports, 6, 37549 , 2016.

63. WANG Z.J., HUANG J.Q., HUANG Y.J., LI Z., BING S.Z. Discovery and profiling of novel and conserved microRNAs during flower development in Carya cathayensis via deep sequencing. Planta, 236, 613, 2012.

64. YANG C.C., YE Y.Y., SONG C., CHEN D., JIANG B., WANG Y. Cloning and functional identification of the AcLFY gene in Allium cepa. Biochemical and Biophysical Research Communications, 473, 1100, 2016. 
65. WANG Z.J., HUANG J.Q., HUANG Y.J., CHEN F.F., ZHENG B.S. Cloning and characterization of a homologue of the FLORICAULA/LEAFY gene in Ficus carica L., $F C L F Y$, and its role in flower bud differentiation. Scientia Horticulturae. 261, 1, 2020.

66. ZHANG C.S., ZHANG H.W., ZHAN Z.X., LIANG Y. Molecular cloning, expression analysis and subcellular localization of LEAFY in carrot (Daucus carota L.). Molecular Breeding 36, 89, 2016.

67. AHMAD S., LI Y.S., YANG Y.J., ZHOU Y., ZHAO K., ZHANG Q. Isolation, functional characterization and evolutionary study of $L F Y 1$ gene in Prunus mume. Plant Cell, Tissue and Organ Culture, 136, 523, 2019.
68. HE F.Q., WANG H.X., ZHANG Z.H. Molecular cloning and sequence analysis of an $L F Y$ homologous gene from Juglans regial. Frontiers of Agriculture in China, 5, 366, 2011.

69. ZHANG T., CHAO Y., KANG J., DING W., YANG Q. Molecular cloning and characterization of a gene regulating flowering time from Alfalfa (Medicago sativa L.). Molecular Biology Reports, 40, 597, 2013.

70. ZHANG Q.L., ZHU Q.H., LIAO X., WANG X.Q., CHEN T., XU H.T., WANG J, YUAN M.L., CHEN J.Y. Selection of reliable reference genes for normalization of quantitative RT-PCR from different developmental stages and tissues in amphioxus. Scientific Reports, 6, 37549, 2016. 